\title{
The experiences of workers who do not successfully return to work following a work-related injury
}

\author{
Rebecca E. Gewurtz ${ }^{\mathrm{a}, *}$, Stephanie Premji ${ }^{\mathrm{b}}$ and D. Linn Holness ${ }^{\mathrm{c}, \mathrm{d}}$ \\ ${ }^{a}$ School of Rehabilitation Science at McMaster University, Hamilton, ON, Canada \\ ${ }^{\mathrm{b}}$ School of Labour Studies and Department of Health, Aging \& Society at McMaster University, \\ Hamilton, ON, Canada \\ ${ }^{\mathrm{c}}$ Dalla Lana School of Public Health and Department of Medicine at the University of Toronto, ON, Canada \\ ${ }^{\mathrm{d}}$ Department of Occupational and Environmental Health, Centre for Research in Inner City Health, \\ and Li Ka Shing Knowledge Institute, St. Michael's Hospital, Toronto, ON, Canada
}

Received 16 October 2017

Accepted 26 March 2018

\begin{abstract}
.
BACKGROUND: A minority of workers with work-related injuries experience challenges returning to work. While factors that hinder return-to-work (RTW) are well-documented, the consequences of failing to successfully return to work on the lives of workers who have experienced a workplace injury remain poorly understood.

OBJECTIVE: The purpose of this study is to explore the experiences of workers who do not successfully return to work following a work-related injury.

METHODS: Using an interpretive approach to qualitative research and maximal variability sampling, 11 workers who have sustained work-related injuries without a successful RTW and four service providers were recruited through community organizations. Participants were interviewed using a semi-structured interview guide. A constant comparative approach was used to identify key themes across the worker and service provider experiences.

RESULTS: The findings that emerged from the analysis capture the challenging RTW experiences of workers and describe wide ranging impacts on their lives when their workers' compensation claims are denied or discontinued, including ongoing financial strain, family tensions, subsequent health concerns, and negative employment experiences. The findings also highlight the negative consequences of existing cost-cutting frameworks that can restrict entitlement and benefits for many people with disabilities.
\end{abstract}

CONCLUSIONS: The findings from this study highlight the experiences of workers who might need additional supports throughout the RTW process, and begin to shed light on the impact on their lives when RTW is not successful.

Keywords: Injured workers, workers' compensation, qualitative research, return-to-work, complex claims

\section{Introduction}

Most workers who experience a work-related injury or illness recover and successfully reintegrate

*Address for correspondence: Rebecca E. Gewurtz, School of Rehabilitation Science at McMaster University, 1400 Main St. W, Hamilton, Ontario, L8S1C7, Canada. Tel.: +1 905525 9140/ Ext. 22189; E-mail: gewurtz@mcmaster.ca. into the workforce. However, a minority experience more complex and prolonged trajectories and are unable to return to or maintain employment [1], even after receiving work reintegration services. For instance, data from the Ontario workers' compensation system, the Workplace Safety and Insurance Board (WSIB), show that only $23 \%$ of the approximately 8,000 workers referred yearly 
to the former work reintegration program ${ }^{1}$ found employment [2]. Both system-level and individuallevel factors may hinder successful return-to-work (RTW), including worker and job characteristics, workplace factors (e.g. accommodations, workplace culture, etc.), aspects of medical care and workers' compensation, and larger societal factors such as macroeconomic conditions [1,3,4]. Although less is known about the impacts of RTW difficulties, a few qualitative and quantitative studies conducted among injured workers who have experienced job loss and precarity document financial hardship [5-8], family and social disruptions [7], depression and alienation [7, 9-11], as well as new work-related injuries and illnesses from working in jobs that were different from those held pre-injury [8]. These impacts intensify the substantial consequences of the injury or illness itself. Indeed, research has found that work-related injuries and illnesses negatively affect physical and mental health - at times persistently and/or through secondary conditions - as well as social and economic dimensions of life through interference with work, domestic and leisure activities, stigmatization, relationship strain and financial hardship [12-19].

Importantly, research suggests that the impacts of work injuries and unsuccessful RTW are mediated by larger systemic and organizational factors. It has been shown that the compensation, rehabilitation, health care and workplace systems shape responses to occupational health problems and RTW matters [20]. A systematic review of the qualitative literature on interactions between injured workers and workers' compensation systems found that negative interactions are commonplace and result in secondary psychological injury, hindering recovery and successful RTW [21]. Specifically, studies have found that interactions between workers and system actors are characterized by power differentials and typically adversarial, which can exacerbate workers' symptoms, cause new pathologies and undermine the motivation to work [22-27]. For example, Kirsh and McKee (2003) surveyed 290 injured workers in Ontario and found that the adversarial claim process impacted career plans, leisure, finances, as well as mental and general health [6]. The claim and RTW process is also characterized by de-legitimization, coercion and stigmatization, which can victimize injured workers and undermine their mental health and, in some cases, their physical health $[7,24,25]$. At

\footnotetext{
${ }^{1}$ In September 2011, the WSIB launched a new "Work Reintegration Strategy".
}

the same time, indifference and disrespect by system actors can lead to distress and frustration, including in the RTW process $[23,28]$. In the workplace, negative attitudes and actions by employers toward injured workers returning to work can result in feelings of self-devaluation, hostility and resentment [29], while lack of attention to accommodations and medical recommendations, as well as unrealistic rehabilitation guidelines, can contribute to adverse impacts on health [6]. Such conditions can threaten the success of RTW attempts by creating untenable working conditions. Erratic, delayed or denied benefits payment can also increase the health, social and financial impacts of work injuries and of failing to return to work successfully $[23,30]$.

In addition to factors upstream, individual-level factors may mediate the experiences of injured workers who do not successfully return to work. Studies have found that such factors as the nature of the injury or illness, psychological symptoms, social support and socio-demographic and economic characteristics help determine RTW outcomes [31-36], however little information exists on how individuallevel factors mediate the impacts of work-related injuries and of failing to return to or maintain employment. Dembe has argued that the consequences of work-related injuries and illnesses fall disproportionately on women, ethnic minorities, immigrants and other vulnerable populations [37]. For example, studies have suggested that women with work injuries and illnesses are more likely to have their credibility questioned [38, 39], while others have shown that immigrants, ethnic and linguistic minorities are more likely to experience problems with workers' compensation, employers and health care providers [40, 41]. Similarly, a recent systematic review identified older age, female gender, divorced marital status, two or more dependent family members, lower education level, reduced labour market desirability, and injury severity as predictors of poor work outcomes following a workplace injury [42]. An understanding of the impacts of RTW difficulties among those who have sustained work-related injuries must therefore incorporate an analysis of system-level and individual-level factors that can modify impacts. This article contributes to this body of research by exploring the experiences of injured workers who have not successfully reintegrated the workforce by drawing on the experiences of injured workers and service providers in Ontario, Canada. Specifically, it reports on research that sought to explore the social, economic and health impacts of a 
challenging and unsuccessful RTW process following a work-related injury or illness on injured workers and their families, and to explore how RTW experiences are shaped by systemic and individual factors.

Each Canadian province has their own workers' compensation legislation, which guides compensation processes, policies, and practices. Therefore, the experiences of workers might vary across jurisdictions. However, there have been recent reports on overall trends across Canada and elsewhere that suggest similar challenges resulting in more stringent eligibility criteria and reduced benefits for individuals who experience work-related injuries and illnesses [43, 44]. In Ontario, although the majority of WSIB claims are resolved with the worker successfully returning to employment, a small proportion of injured workers are classified as having a permanent impairment based on the nature of the injuries and acknowledgement that full recovery is unlikely [45, 46]. A significant minority of injured workers have their claims denied, often due to ambiguity about the nature of the injury, its relationship to the workplace, and pre-existing health state [46]. Those receiving WSIB benefits are typically expected to return to employment upon recovery. However, failure to meet the expected RTW milestones might result in a discontinuation or reduction of benefits $[34,36]$. This research is focused on individuals who have complex claims and did not successfully return to employment following a work-related injury or illness.

In this paper we use the term "injured worker" rather than person-first language, "workers with injuries" or "people who have experienced workers injuries". The term "injured worker" is used throughout the existing literature and by injured workers themselves. It is also consistent with the social model of disability which guided this research, giving prominence to how experiences are shaped by social forces, structures, and conditions [47-49].

\section{Methods}

This research applied an interpretive qualitative research approach [50] to examine what happens to injured workers in Ontario, Canada when RTW is not successful. It draws on the perspectives of injured workers who have experienced unsuccessful RTW and service providers who work with injured workers with complex and contested WSIB claims. For the purpose of this study, unsuccessful RTW is defined as not returning to work as expected (to the same job or equivalent), resulting in unemployment or underemployment. This research was guided by the following three questions:

1) What are the social, economic and health implications of failing to successfully return to work on injured workers and their families?

2) How are workers' experiences shaped by their interactions with disability benefit systems?

3) How are workers' experiences shaped by social vulnerabilities?

\subsection{Data collection}

Eleven injured workers who were unsuccessful at returning to work following a work-related injury and four service providers who work with injured workers with challenging RTW processes participated in indepth interviews about their experiences. This sample size was sufficient to capture a range of diverse experiences, provide rich reflections, achieve saturation of key themes, and identify critical areas for further exploration [51, 52]. We used maximal variability sampling to obtain diversity in individual characteristics that may impact RTW experiences, such as: the nature of injury, employment background, education level, age, gender, language, citizenship, and ongoing disability. We opened up recruitment to injured workers who did not have fluent English conversation skills in order to capture vulnerabilities related to language by offering a professional interpreter/translator in the interviews. We also included individuals with diverse experiences with workers' compensation benefits, accessing work reintegration services, returning to work, and applying for and receiving government sponsored disability and social assistance benefits. This variability in the sampling allowed us to capture a range of issues and complex vulnerabilities that can impact the experiences of injured workers. Participants were limited to the Greater Toronto and Hamilton Area (GTHA).

Following ethics approval from the Hamilton Integrated Research Ethics Board, potential participants were recruited first through our community partners (two non-profit legal clinics and a community health centre). Additional participants were recruited through support groups for injured workers in the GTHA who agreed to circulate information about the study through their networks. Individuals who were interested in participating after hearing about the study contacted the research office. Interviews were conducted in private rooms at libraries, community 
centres and associations, or the offices of one of our partner organizations, depending on the preference of each participant. All interviews were conducted by the same research assistant, a graduate student with training in qualitative research. The graduate student explained the study to participants and received consent to proceed with the interview both verbally and in writing. The interview guide was developed by the research team, with input from community partners, and modified after the first interview to ensure we gathered rich data in answer to our research questions. Participants were asked about their experiences accessing workers' compensation benefits and services and attempting to return to work. Questions revolved around the social, economic and health consequences of unsuccessful RTW, and the structural and individual factors that shaped their experiences. Interviews lasted approximately $1 \frac{1}{2}$ hours and were semi-structured to allow us to freely explore unique lines of inquiry with each participant.

\subsection{Data analysis}

Interviews were digitally recorded and transcribed. Data was managed with Dedoose software. Interview segments were coded using a mixed coding strategy whereby codes are partly defined a priori - meaning that they were informed by relevant findings from the literature - and partly defined during analysis. Initial coding was completed by a pair of graduate students with training in qualitative research, with regular meetings with the principal investigator and the full research team. All coding was reviewed by the principal investigator and coding decisions were discussed amongst the research team. The codes were grouped into themes that were used to generalize the data into theory using a constructivist grounded theory approach [50]. In addition, we explored the data collected from the injured workers to map their RTW trajectories from the time of injury onwards, including their interactions with the workers' compensation system and their workplace, to identify points of friction in the RTW process and impacts on workers and their families [53]. We used the data collected from service providers to fill in details about how the system operates more broadly, and common barriers faced by those who experience challenges. We then explored the most significant and prevalent themes and concepts from across the trajectories from the perspectives of injured workers and service providers. This process enabled us to examine how the experiences of injured workers varied under different circumstances [50, 54].

\section{Findings}

The findings reported here focus on the impact of unsuccessful RTW among injured workers who experienced complex RTW trajectories and did not return to work as expected. The findings capture their trajectories over time, shaped by multiple and contentious interactions with the workers' compensation system, and their social position as related to gender, poverty, disability, immigration status, language, and social class.

\subsection{Participants}

Injured workers who participated in this research ranged in age from 38 to 69 years (Mean $=51$ years, Median $=52$ years). Injuries were mostly musculoskeletal, and ranged from traumatic onset to those resulting from repetitive strain. The length of time since the injury occurred was between 15 months and 28 years (Mean $=12$ years, Median $=7$ years). There were six women and five men. Although we recruited two participants who were new to Canada and spoke English as a second language, we only employed the assistance of a professional interpreter/translator in one of the interviews. At the time of the interviews, eight were unemployed and three worked part-time in positions unrelated to their previous employment. Although all the participants had applied for workers' compensation, two were denied, five were initially accepted but one was subsequently discontinued, and four were in appeal. All of the participants reported that they informed their employer of their injury, however, the timing of this reporting varied. The majority of the participants reported their injury immediately, especially when the injury was traumatic and required immediate medical attention. However, some participants described a period of trying to cope on their own, without acknowledging the injury or reporting it to their supervisor or employer.

Participants generally described their pre-injury life as unremarkable. They described themselves as relatively financially stable, in good overall health, with supportive family relationships and strong social ties. A few participants noted preexisting health conditions and two participants were new to the Canadian workforce. None of the participants had previous experience with the workers' compensation system. 
More than half of the participants worked in factories and most had put in several years at their workplace. A few participants noted that there was a history of injuries at their job site and that workplace safety was considered a low priority by their employer.

The service providers were selected to provide different perspectives gained from working with injured workers who have experienced challenging RTW trajectories, specifically: legal, workplace, health, and labour. Service providers had been involved in working with injured workers for between 3 and 23 years. Tables 1 and 2 provide a summary of the participants. Pseudonyms are used throughout the presentation of the findings to protect the anonymity of the participants.

\subsection{Impact of unsuccessful RTW}

Both injured workers and service providers described multiple consequences associated with failing to successfully return to work following a workplace injury. The consequences are discussed below, and include: 1) financial strain; 2) family tensions; 3) subsequent health concerns; 4) negative employment experiences and outcomes, and; 5) stigma. These findings are discussed along the RTW trajectory (from the time of injury onwards) and demonstrate the profound impact an injury can have, when RTW does not progress as expected.

\subsubsection{Financial strain}

All participants discussed the various ways in which failing to successfully return to work led to a significant financial burden. Although all of the injured workers who participated in the interviews had submitted a claim for workers' compensation to the Ontario Workplace Safety and Insurance Board (WSIB), only four were receiving income replacement benefits at the time of their participation. Decisions to deny or discontinue benefits were complex and based on a multitude of factors; however, a common explanation provided by participants was recovery of the initial compensable injury despite ongoing work disability due to secondary or subsequent injury or health conditions. Among those not receiving benefits from the WSIB, three indicated they had no income, one was receiving provincial social assistance through Ontario Works (the general welfare program), two were receiving benefits from the national pension plan (contribution-based pension for Canadian workers), and one was relying on income earned from a part-time job. Those receiving no income described accessing their savings or relying on support from family. Those working at part-time jobs described a significant reduction in their earnings. Participants also discussed their interactions with Employment Insurance (EI), the Ontario Disability Support Program (general welfare program for people with disabilities), and company-sponsored disability plans. Some participants described how difficult it was to access other benefit systems as an injured worker, since most systems were sending them back to workers' compensation to settle their workplace claim before providing benefits of last resort through the social assistance programs available in Ontario. Overall, navigating the different benefit programs was described as challenging. Even after many years since being injured at work, some participants were unsure what to do and where to turn for ongoing financial support. One participant who worked in a unionized environment at the time of his injury seven years ago described his experience trying to navigate multiple benefit systems as an injured worker, and the challenges he faced trying to secure income supports:

ODSP [the Ontario Disability Support Program] won't touch me because I have WSIB. Long-term disability from [name of employer] doesn't cover me because I'm on WSIB. And long-term [disability] cuts you off because you still have sick credits at work and you can't go on long-term until you've used up all your sick credits but you can't use up all your sick time because you're not at work. And you're still accumulating it [sick credits] every month even though you're injured. So you can never get on long-term [disability] insurance. (Daniel, age 38)

Injured workers whose claims were denied or discontinued expressed their confusion and disappointment in the workers' compensation system: "I want WSIB to reinstate me because there's no reason why injured workers should be on a different system than WSIB when they are not recovered..." (Jane, age 35).

All of the participants described accumulating costs related to lost wages, legal fees, and ongoing medical treatment (e.g. therapy and medication) for the original and subsequent injuries that were not covered by either the provincial health care system, the workers' compensation system or other sources. The significant financial burden that resulted from these factors led, in some cases, to loss of housing and savings, credit card and other debt, and difficulty 
Table 1

Summary of Participants - Injured Workers

\begin{tabular}{|c|c|c|c|c|c|c|c|}
\hline $\begin{array}{l}\text { Injured } \\
\text { Worker } \\
\text { (Pseudonym) }\end{array}$ & Age/Gender & $\begin{array}{l}\text { Job at the } \\
\text { Time of Injury }\end{array}$ & Nature of Injury & $\begin{array}{l}\text { Length of time } \\
\text { since work } \\
\text { injury }\end{array}$ & $\begin{array}{l}\text { Status with } \\
\text { Workers' } \\
\text { Compensation } \\
\text { (WC) }\end{array}$ & $\begin{array}{l}\text { Employment } \\
\text { Status }\end{array}$ & $\begin{array}{l}\text { Current Source of } \\
\text { Income }\end{array}$ \\
\hline Kobby & 51 Male & Factory & $\begin{array}{l}\text { Injured right } \\
\text { hand }\end{array}$ & 5 years & Benefits ended & Unemployed & No income \\
\hline Marie & 53 Female & Letter carrier & $\begin{array}{l}\text { Hip, knee and } \\
\text { wrist injuries }\end{array}$ & 10 years & $\begin{array}{l}\text { Receiving WC } \\
\text { benefits; } \\
\text { Sent for } \\
\text { retraining }\end{array}$ & $\begin{array}{l}\text { Employed } \\
\text { Part-time }\end{array}$ & WC Part-time job \\
\hline Sarah & 52 Female & Factory & $\begin{array}{l}\text { Repetitive hand } \\
\text { injury }\end{array}$ & 23 years & $\begin{array}{l}\text { Pending } \\
\text { appeal }\end{array}$ & Unemployed & No income \\
\hline Jane & 35 Female & Car cleaner & $\begin{array}{l}\text { Concussion, } \\
\text { whiplash, } \\
\text { fractured rib }\end{array}$ & 15 months & $\begin{array}{l}\text { Pending } \\
\text { appeal }\end{array}$ & $\begin{array}{l}\text { Employed } \\
\text { Part-time }\end{array}$ & Part-time job \\
\hline Emma & 55 Female & Factory & $\begin{array}{l}\text { Repetitive } \\
\text { strain, back } \\
\text { injuries }\end{array}$ & $\begin{array}{l}1 \text { year, } 9 \\
\text { months }\end{array}$ & Claim denied & Unemployed & No income \\
\hline Daniel & 38 Male & Letter carrier & $\begin{array}{l}\text { Sprained ankle, } \\
\text { blood clots } \\
\text { damaged nerves }\end{array}$ & 7 years & $\begin{array}{l}\text { Receiving WC } \\
\text { benefits; } \\
\text { Sent for } \\
\text { retraining }\end{array}$ & $\begin{array}{l}\text { Unemployed } \\
\text { Student }\end{array}$ & $\mathrm{WC}$ \\
\hline Clara & 47 Female & Factory & Back injury & 3 years & $\begin{array}{l}\text { Pending } \\
\text { appeal }\end{array}$ & $\begin{array}{l}\text { Employed } \\
\text { Part-time }\end{array}$ & Social Assistance \\
\hline Mike & 52 Male & Factory & $\begin{array}{l}\text { Foot crushed, } \\
\text { severed toes }\end{array}$ & 28 years & $\begin{array}{l}\text { Receiving WC } \\
\text { benefits; } \\
\text { Sent for } \\
\text { retraining }\end{array}$ & Unemployed & WC \\
\hline Ling & 59 Female & $\begin{array}{l}\text { Personal } \\
\text { Support } \\
\text { Worker }\end{array}$ & $\begin{array}{l}\text { Head and lower } \\
\text { back injuries }\end{array}$ & 7 years & $\begin{array}{l}\text { Receiving WC } \\
\text { benefits; } \\
\text { Sent for } \\
\text { retraining }\end{array}$ & Unemployed & WC \\
\hline Victor & 54 Male & Factory & $\begin{array}{l}\text { Lower back } \\
\text { injury }\end{array}$ & 23 years & $\begin{array}{l}\text { Pending } \\
\text { appeal }\end{array}$ & Unemployed & $\begin{array}{l}\text { Canadian Pension } \\
\text { Plan, Disability }\end{array}$ \\
\hline James & 69 Male & Electrician & $\begin{array}{l}\text { Right shoulder, } \\
\text { rotated cuff } \\
\text { injury }\end{array}$ & 14 years & Claim denied & Unemployed & $\begin{array}{l}\text { Canadian Pension } \\
\text { Plan and Old Age } \\
\text { Security }\end{array}$ \\
\hline
\end{tabular}

accessing essential items such as food. Participants mourned their plans for the future: "I would have had golden years. I had a pension and all that but, you know what, I had to rob my pension to pay off some of the additional costs that I had between the lawyers" (James, age 69). Participants described how there was little follow-up or concern for what happens to injured workers after their workers' compensation benefits were terminated or when their claim was denied. They described the challenge of recovery under such circumstances, and how financial strain led to further mental and physical health problems. For example, Emma (age 55) whose claim was denied, stated the following almost two years after she experienced her injury:

Five months I'm without a cent. Nobody knows if I'm just boiling water and drinking it or putting a sock in it or whatever... You don't go out and tell people this is how you're going to live in your house, and at the same time they expect you to get healthier, to emotionally be better, to physically be better. On what? If you're only eating carbs all the time, how can you get healthy?

The service providers echoed these concerns by noting the rapid decline into poverty in cases where workers' compensation benefits are denied or discontinued because other benefit programs such as social assistance, when accessed, provide significantly less than pre-injury earnings: "Social programs do not provide nearly enough money to live on. It absolutely creates poverty" (Community Legal Worker, SP4).

Injured workers who are also newcomers to Canada faced additional challenges trying to navigate the workers' compensation system and other disability benefit systems following a workplace injury. Such issues were raised by both injured workers and 
Table 2

Summary of Participants - Support Persons

Return to Work Coordinator (Employer)

Injured Worker Specialist (Health, Hospital-based clinic)

Labour Relations Officer (Union)

Community Legal Worker (Legal)

service providers who highlighted challenges related to English language proficiency and understanding eligibility criteria, requirements, and provisions. These challenges intensified the confusion experienced by some injured workers.

\subsubsection{Family tensions}

All of the injured worker participants discussed the impact that their unsuccessful RTW had on their family relationships. Some highlighted the support they received from family that enabled them to persevere. As an example, one participant who experienced a traumatic workplace injury many years ago described the importance of the support he received from family and friends:

I think I've had a good support system with my wife and family, friends that help me. Because I know I've gone through some really bad bouts of depression and things like that, but they help me through. It's been tough but you got to keep going. (Mike, age 52)

However, even among those reporting positive familial relationships and support, some expressed apprehension about the lasting nature of these relationships in light of the strain placed on marriages and relationships with children. Both injured workers and service providers described how workplace injuries and unsuccessful RTW altered roles and responsibilities within their family. In many cases these changes resulted in ongoing strain, resentment and misunderstandings: "Family doesn't want to deal with you because you' re stressed out all the time when you're trying to deal with something. They don't understand what it's like" (Daniel, age 38). Some of this strain was caused by financial hardship, as described by one participant:

I have kids to take care of. They have their own needs. I can't go to the store and tell them my kids need shoes or my kids need underwear. I can't go to the store and say my kids need food. (Emma, age 55)

Those with family in other countries described the added challenge of communicating their situation and explaining why they could no longer send money home or continue with sponsorship plans. Such circumstances led to further frustration and disappointment, thereby straining family relationships. In some cases, the injured workers described being estranged from family members and mourned the loss of these sources of support and their meaningful familial roles. Others distanced themselves from their families because they no longer felt capable of providing for them and felt ashamed for their current circumstances.

\subsubsection{Subsequent health concerns}

Most participants discussed the subsequent pain, injury, or illness experienced as a result of their interactions with workers' compensation, early and unsuccessful attempts returning to work, and a lack of adequate accommodations at work. These subsequent health concerns included descriptions of psychological distress and mental illness, as well as ongoing physical health problems. These health problems seemed to persist even years after the initial injury and seemed to have important impacts on the day-to-day experiences of injured workers.

Depression and anxiety was quite prevalent in the experiences reported by both the injured worker and service provider participants. Many participants described depression resulting from the initial injury, chronic pain, and resulting disability. Others described depression and anxiety in relation to failed attempts returning to work. However, in some cases, mental distress was described more broadly in terms of trying to navigate the system and manage their own recovery, resulting in feeling unsupported and abandoned. For example, one participant described this ongoing struggle: "I've been on depression meds for two years now.... It's hard when you're still trying to navigate the system and still finding barriers after seven, almost eight years" (Daniel, age 38). Another participant described feeling suicidal following her interactions with a WSIB case manager: "They pushed me to the point where I felt like jumping off the balcony and they had to call the police and I ended up in the psychiatric ward" (Emma, age 55). These concerns were echoed by a service provider who highlighted the ongoing frustration she observed among injured workers trying to navigate the workers' compensation system from her perspective working in a legal clinic: "It's incredibly frustrating and anxiety provoking ... it delegitimizes them and there's a dignity and respect issue that has very real consequences" (SP4). 
The experience of psychological distress, anxiety and depression made it difficult for injured workers to engage in their daily activities, as well as activities related to their recovery and procedural responsibilities related to their claim. Several participants described how depression led to isolation and separation from supports, including family and friends. It often prevented injured workers from participating in social activities, leisure pursuits and volunteer activities. As reported by one participant: "Oh wow, like I said, I used to play sports. That was a big part of my social life. I don't do that anymore. Since depression, there is a lot of times that I just don't leave the house" (Sarah, age 52).

Subsequent physical health problems were also described by the participants as being quite prevalent. In some cases, such health concerns were described in relation to their experience of psychological distress and stress that resulted from their interactions with workers' compensation: "Inever had blood pressure problems in my life until this all started getting bad and I started getting messed around by WSIB" (Mike, age 52). Other injured workers described being reinjured during their involvement with work reintegration, and expressed significant frustration of the impact of their secondary injury on their RTW trajectory: "I never got back to work. I got reinjured. WSIB had reinjured me in a program, given me an extra tear, given me a hernia" (James, age 69).

\subsubsection{Negative employment experiences and outcomes}

Both injured workers and service providers discussed the ways in which injured workers were pressured to return to work before they were ready. Some of these pressures were internal, such as the need to make money. However, many were external. These external pressures came mainly from employers and the workers' compensation system, seeking to limit lost time claims due to costs. At times, these pressures were inconsistent with recommendations from healthcare providers: "I was told by WSIB that I have to start at four hours and that they would ignore my doctor's letter. So this is the problem we're having with WSIB. I was forced back to work" (Emma, age 55). This conflicting information led to confusion and misunderstandings among injured workers. As well, it put some workers at risk for re-injury, as they felt obligated to return to work as instructed or lose access to benefits and supports: "They [WSIB] just sent a letter, you know... we have a certain period, window in which that should happen, and that's happened. Either you go back to work or we stop paying you" (Victor, age 54). Not surprisingly, these early attempts often ended unsuccessfully, leading to unemployment and benefits being altered, reduced, or discontinued.

A few participants noted that such circumstances were caused, in part, by the rigid categorization of injuries that does not always take into account the complexity of each circumstance and variability in the rehabilitation process. As a result, workers described being deemed "job ready" prematurely, even when they were unable to find suitable employment. As a result, their income benefits were reduced or discontinued. As an example, one participant who experienced a broken leg that led to further vascular injuries, described his situation as follows:

They've lumped me into the broken leg category where somebody breaks their leg, is off six weeks, then they go back to work. That's what WSIB assumes I should be able to do because there's no category for vascular injuries or blood clots or deteriorated veins or anything. There's no classification for that. So they just put you in a certain category and expect that you're going to have the same results as everybody else. WSIB is too single minded. (Daniel, age 38)

Several injured workers also discussed various ways in which their employers failed to provide them with the appropriate accommodations to safely return to work. For example, participants described being asked to complete work tasks that did not meet their medical restrictions, or feeling like they were being pushed beyond their limits. In some cases, workers felt this was a strategy to encourage them to quit "They said modified job, but it's not. It's even heavier than when I was injured because they want me to quit the job myself' (Ling, age 59). Another participant describes being in a state of limbo, where her employer did not fire her, but rather waited for her to quit due to lack of a job: "Since 2011 the employer didn't give me any job and they didn't lay me off" (Ling, age 59). However, in some cases, workers were directly terminated. For example, one injured worker described being told he was no longer needed because his job was redundant, only to have the position filled by a non-injured worker: "It was horrifying! How do you tell somebody they can no longer work here and the position doesn't exist and then six weeks later you have a bid for it? That doesn't make any sense" (Daniel, age 38). 
A shared experience by participants was that the rigid rules within the workers' compensation system served to limit their employment options. A component of the reintegration program offered by the WSIB is centered on recommendations of jobs for the injured worker. Participants noted that little effort was made to identify jobs that were well matched to their skills and interests, often resulting in recommendations for jobs that were viewed as less meaningful, perpetuating underemployment and deskilling. As an example, one participant who was a nurse in her country of origin and worked as a personal support worker before her injury described being retrained for a job at a laundromat rather than respecting her desire to stay within a health-related field: "So my qualifications - I can do the needle injection and I want to find some a job in the future like related to being a nurse. But WSIB sent me to lessons for laundry" (Ling, age 59). In other cases, job reassignment required relocation or a financial downgrade. Several participants felt that expectations were unreasonable, providing insufficient time for recipients to secure employment before benefits were terminated.

\subsubsection{Stigma}

Stigma was a prevalent theme reported by the injured worker participants. Stigma was described by injured workers in two ways: First, it was described in relation to interactions with co-workers, employers, supervisors and workers' compensation staff. In addition, stigma was described more generally, in terms of their position as injured workers and person with disabilities.

Workplace stigma centered on experiences attempting to return to work post-injury and secure workplace accommodations. Injured workers described overt harassment and discrimination. For example, one participant described how her supervisor encouraged her coworkers to treat her as if she was a threat and was getting special treatment:

The supervisor had gathered all of the employees in that final section and told them who I was. Told them my name, who I was, that I was an injured worker and that I only wanted to stay home and to collect a cheque and that I was out for their job...everyone thought I was being treated special. I wasn't being treated special, I was just getting the things to help me work. (Marie, age 53)

Participants also described more general social stigma that made it difficult for them to return to work or feel good about themselves. This stigma extended beyond the workplace and many participants noted that they feared going out because people often assumed that if they were unable to work they should look sick and be unable to engage in other aspects of life. Some participants described how these circumstances made it difficult for them to find a new job. For example, one participant described the difficulty she encountered trying to find a new job and noted, "when you hurt, nobody wants to employ you" (Emma, age 55). Another participant specifically highlighted how employers fear disability and injured workers: "I still don't get hired, you tell me why? I don't know. I think people, employers, are scared from the people who's on disability" (Clara, age 47).

\section{Discussion}

This research documents the experiences of a small sample of individuals with complex RTW trajectories who were unsuccessful returning to work following a work-related injury. The findings highlight the broad financial, social, and health consequences on individuals and their families, as they interact with the workers' compensation system over time. In some cases, they become disconnected from the workers' compensation system altogether and find themselves navigating other systems of support. The findings reported here highlight the prevalent and persistent nature of the ongoing financial, health, and social needs of injured workers that are often downloaded to other social support systems when workers' compensation is no longer available [55]. These findings are consistent with existing evidence that has demonstrated how employer-sponsored disability benefit programs, such as workers' compensation boards, have pursued cost cutting neoliberal agendas, leading to reforms that have restricted entitlement and reduced benefits for many Canadians with disabilities [43, 44]. This eroding of disability benefits in Canada has implications for social assistance programs, who are generally ill-equipped to meet the growing demand [43]. Furthermore, social assistance typically provides lower rates. Thus, there is growing concerns about poverty among those who have sustained a work-related injury despite the coverage and protection offered by workers' compensation benefits [55]. The reliance on other benefit systems among injured workers highlighted here has not been thoroughly documented or examined in the scientific literature. However, advocates have raised concerns 
about the downloading of benefits for injured workers to social assistance $[8,55]$. There is an ongoing need to explore the prevalence of these experiences and the extent to which injured workers are entering social assistance programs, as well as those who are unable to secure income replacement benefits.

Importantly, the population of injured workers featured in this research has been underrepresented in scientific literature [27, 55], and their experiences have not been documented by workers' compensation systems since there is no follow-up once benefits are denied or discontinued [56]. The urgency to improve reporting, follow-up and accountability has been noted in a recent report by Industrial Accident Victims Group of Ontario, which highlights that cost-saving efforts within the WSIB has resulted in complex claims being denied or discontinued despite compelling medical evidence and recommendations from treating health care professionals [46]. Premature return to work can further jeopardize the health, safety and security of workers who have sustained work-related injuries. The findings reported here suggest that such practices have been longstanding within the system and showcase the impact on injured workers and their families. Beyond risk of re-injury, premature return to work can lead to long-term unemployment and underemployment. Specifically, the experiences highlighted in this paper suggest that injured workers who have been unsuccessful in the RTW process live with significant fear and uncertainty towards the future, and endure significant income insecurity and poverty. Experiences of complex health challenges and cumulative social vulnerabilities seem to exacerbate the impact of unsuccessful attempts returning to work and amplify the negative experiences and outcomes associated with being an injured worker and interacting with the workers' compensation system. In some cases, individuals find themselves with fewer options for work and benefits, leading to a rapid spiral into poverty. Importantly, these negative impacts seem to persist several years following the initial injury.

Furthermore, research has highlighted the unique vulnerabilities experienced by injured workers who are new to Canada and experience linguistic barriers negotiating access to benefits and services returning to work [34]. Our study adds to this literature by highlighting, for example, how the identification of "suitable work" by the WSIB may in fact contribute to professional deskilling among highly qualified newcomers. Improved understanding of the long-term experiences of injured workers who do not successfully return to work is critical in order to better respond to their ongoing needs.

Some of the injured workers who participated in this research experienced their injury several years ago, prior to the institution of the new work reintegration program. New WSIB data indicates that $92 \%$ of injured workers return to work [45]. However, little is known about what happens to workers after the benefits are discontinued [55]. The findings presented here suggest that some might be reinjured or experience job loss. Others might linger on public benefits, or end up in part-time positions unrelated to their skills and qualifications, offering less security, benefits and lower earnings. Given the limited scope of our project, our analysis did not detect differences between workers who had experienced more recent injuries and those whose injuries had occurred several years ago around key issues such as work reintegration, retraining, and determining readiness to return to work. However, WSIB data suggests that benefits have become more stringent and that less long-term benefits are being awarded [46].

The findings reported here suggest that work retraining can result in significant deskilling, positioning injured workers for jobs that are unrelated to their skills and interests and may not be available in the local job market. The findings also highlight incidents of "deeming", where workers are considered job-ready by the workers' compensation system and benefits are reduced or discontinued even when the worker is unable to secure employment. Deeming can lead to underemployment and reduced income security.

Although this research offers initial insight into the experiences of injured workers who have not successfully returned to work and individuals who work with injured workers, the perspectives of families, employers and co-workers were not explored. Further understanding of the experiences of diverse stakeholders is critical. In particular, the findings reported here suggest that family members play critical roles in supporting injured workers whose benefits have been denied or discontinued. Such circumstances can cause significant strain and stress on the family unit, leading to further insecurity and vulnerability. Understanding the role of family in the experiences of injured workers is emergent [57] and requires further attention.

Finally, the limited scope of our study reduced our capacity to fully explore the interrelationships between diverse vulnerabilities, including the impact 
of different types of injuries and different types of jobs. However, the findings suggest that social and physical vulnerabilities play an important role in the RTW experiences of injured works who might face additional challenges securing benefits, retraining, securing post-injury employment and daily life with a chronic injury or illness $[27,34,58]$. This line of inquiry requires further study using mixed methods to explore these interactions and how they evolve over time.

Although the focus of this research was the Ontario workers' compensation system, many jurisdictions throughout Canada and across other developed countries are encountering similar challenges. We expect that the findings here have application beyond Ontario in terms of the challenges encountered by injured workers with unsuccessful RTW trajectories who become disconnected from the system. There is a need to further examine and track what happens to injured workers overtime, and the long-term consequences of workplace injuries to workers and their families, especially among workers with multiple and cumulative vulnerabilities.

\section{Conclusions}

The findings highlight the need for further examination of injured workers who do not successfully return to work. Although the need to better coordinate different benefit systems has previously been highlighted [55], the findings reported here suggest that injured workers who do not successfully return to work face multiple and cumulative negative impacts associated with their experience with the workers' compensation system. There is a need to better track the experiences of injured workers who are unsuccessful returning work after a workplace injury to identify challenges and opportunities for system improvements. Such efforts are particularly pressing in the current context of cost containment.

Compliance with Ethical Standards.

\section{Acknowledgments}

This study was funded by a Seed Grant from the Centre for Research on Work Disability Policy (Social Sciences and Humanities Research Council Award 895-2012-1017). We wish to acknowledge the contributions of Katie Cook, Xavier Bromfield,
Maria Guindy and Stacey Mitchell who worked on aspects of this project. We also wish to thank the participants who shared their experiences and our community partners at Injured Workers Consultants, Industrial Accident Victims' Group of Ontario, and Bramalea Community Health Centre who assisted with recruitment and data collection.

\section{Conflict of interest}

No potential conflict of interest was reported by the authors.

\section{Ethical approval}

All procedures followed were in accordance with the ethical standards of the responsible committee on human experimentation (institutional and national) and with the Helsinki Declaration of 1975, as revised in 2000 [5]. Informed consent was obtained from all patients for being included in the study.

\section{Funding}

This study was supported by a Seed Grant from the Centre for Research on Work Disability Policy (Social Sciences and Humanities Research Council Award 895-2012-1017).

\section{Informed consent}

Informed consent was obtained from all individual participants included in the study.

\section{References}

[1] MacEachen E, Kosny A, Ferrier S, Chambers L. The "toxic dose" of system problems: Why some injured workers don't return to work as expected. Journal of Occupational Rehabilitation. 2010;20(3):349-66.

[2] Workplace Safety and Insurance Board. Work reintegration program Toronto2014 [Available from: http://www. wsib.on.ca/en/community/WSIB/ArticleDetail?vgnextoid= 5ae011e6c12e0310VgnVCM100000469c710aRCRD.

[3] Krause N, Frank JW, Dasinger LK, Sullivan TJ, Sinclair SJ. Determinants of duration of disability and return-towork after work-related injury and illness: Challenges for future research. American Journal of Industrial Medicine. 2001;40(4):464-84. 
[4] MacEachen E, Clarke J, Franche R-L, Irvin E. Systematic review of the qualitative literature on return to work after injury. Scandinavian Journal of Work, Environment \& Health. 2006;32(4):257-69.

[5] Ontario Network of Injured Workers Groups. Injured workers and poverty survey. Toronto; 2010.

[6] Kirsh B, McKee P. The needs and experiences of injured workers: A participatory research study. WORK. 2003;21(3):221-31.

[7] Beardwood BA, Kirsh B, Clark NK. Victims twice over: Perceptions and experiences of injured workers Qualitative Health Research. 2005;15(1):30-48.

[8] Gadoury C, Lafrance R. Quand la réadaptation professionnelle mène á l'appauvrissement et á la précarité d'emploi: Union des travailleurs et travailleuses accidenté -e-s de Montréal; 2016 [Available from: https://uttam. quebec/readap/Rapport-de-recherche-sur-la-readaprationprofessionnelle.pdf].

[9] Franche RL, Carnide N, Hogg-Johnson S, Côté P, Breslin FC, Bültmann U, et al. Course, diagnosis and treatment of depressive symptomatology in workers following a workplace injury: A prospective cohort study. The Canadian Journal of Psychiatry. 2009;54(8):534-46.

[10] Cacciacarro L, Kirsh B. Exploring the mental health needs of injured workers. Canadian Journal of Occupational Therapy. 2006;73(3):178-87.

[11] Stice BD, Dik BJ. Depression among injured workers receiving vocational rehabilitation: Contributions of work values, pain, and stress. Journal of Occupational Rehabilitation. 2009;19(4):354-63.

[12] Keogh JP, Nuwayhid I, Gordon JL, Gucer PW. The impact of occupational injury on injured worker and family: Outcomes of upper extremity cumulative trauma disorders in Maryland workers. American Journal of Industrial Medicine. 2000;38(5):498-506.

[13] Boden LI, Biddle EA, Spieler EA. Social and economic impacts of workplace illness and injury: Current and future directions for research. American Journal of Industrial Medicine. 2001;40(4):398-402.

[14] Strunin L, Boden LI. Family consequences of chronic back pain. Social Science \& Medicine. 2004;58(7):1385-93.

[15] Lax MB, Klein R. More than meets the eye: Social, economic, and emotional impacts of work-related injury and illness. New Solutions: A Journal of Environmental and Occupational Health Policy. 2008;18(3):343-60.

[16] Brown JA, Shannon HS, Mustard CA, McDonough P. Social and economic consequences of workplace injury: A population-based study of workers in British Columbia, Canada. American Journal of Industrial Medicine. 2007;50(9):633-45.

[17] Dembe AE. The social consequences of occupational injuries and illnesses. American Journal of Industrial Medicine. 2001;40(4):403-17.

[18] Kirsh B, Slack T, King CA. The nature and impact of stigma towards injured workers. Journal of Occupational Rehabilitation. 2012;22(2):143-54.

[19] Dionne CE, Bourbonnais R, Frémont P, Rossignol M, Stock SR, Laperrière E. Obstacles to and facilitators of return to work after work-disabling back pain: The workers' perspective. Journal of Occupational Rehabilitation. 2013;23(2):280-9.

[20] Soklaridis S, Ammendolia C, Cassidy D. Looking upstream to understand low back pain and return to work: Psychosocial factors as the product of system issues. Social Science \& Medicine. 2010;71(9):1557-66.
[21] Kilgour E, Kosny A, McKenzie D, Collie A. Interactions between injured workers and insurers in workers' compensation systems: A systematic review of qualitative research literature. Journal of Occupational Rehabilitation. 2015;25(1):160-81.

[22] Kilgour E, Kosny A, McKenzie D, Collie A. Healing or harming? Healthcare provider interactions with injured workers and insurers in workers' compensation systems. Journal of Occupational Rehabilitation. 2015;25(1): 220-39.

[23] Roberts-Yates C. The concerns and issues of injured workers in relation to claims/injury management and rehabilitation: The need for new operational frameworks. Disability and Rehabilitation. 2003;25(16):898-907.

[24] Lippel K. Workers describe the effect of the workers' compensation process on their health: A Quebec study. International Journal of Law and Psychiatry. 2007;30(45):427-43.

[25] MacEachen E, Kosny A, Ferrier S. Unexpected barriers in return to work: Lessons learned from injured worker peer support groups. WORK. 2007;29(2):155-64.

[26] Korzycki M, Korzycki M, Shaw L. Left behind in the returnto-work journey: Consumer insights for policy change and practice. WORK. 2008;30:277-87.

[27] Saunders SL, MacEachen E, Nedelec B. Understanding and building upon effort to return to work for people with longterm disability and job loss. WORK. 2015;52(1):103-14.

[28] Parrish M, Schofield T. Injured workers' experiences of the workers' compensation claims process: Institutional disrespect and the neoliberal state. Health Sociology Review. 2005; 14(1):33-46.

[29] Strunin L, Boden LI. Paths of reentry: Employment experiences of injured workers. American Journal of Industrial Medicine. 2000;38(4):373-84.

[30] Strunin L, Boden LI. The workers' compensation system: Worker friend or foe? American Journal of Industrial Medicine. 2004;45(4):338-45.

[31] Blank L, Peters J, Pickvance S, Wilford J, MacDonald E. A systematic review of the factors which predict return to work for people suffering episodes of poor episodes of mental health. Journal of Occupational Rehabilitation. 2008;18(1):27-34.

[32] Holness DL. Workers with occupational contact dermatitis: Work outcomes and return to work process in the first six months following diagnosis. Journal of Allergy. 2011;2011.

[33] St-Arnaud L, Bourbonnais R, Saint-Jean M, Rhéaume J. Determinants of return-to-work among employees absent due to mental health problems. Relations Industrielles/Industrial Relations. 2007;62(4):690-713.

[34] Premji S. Barriers to return-to-work for linguistic minorities in Ontario: An analysis of narratives from appeal decisions. Journal of Occupational Rehabilitation. 2015;25(2):357-67.

[35] Lin KH, Guo NW, Shiao SC, Liao SC, Hu PY, Hsu JH, et al. The impact of psychological symptoms on return to work in workers after occupational injury. Journal of Occupational Rehabilitation. 2013;23(1):55-62.

[36] He Y, Hu J, Yu IT, Gu W, Liang Y. Determinants of return to work after occupational injury. Journal of Occupational Rehabilitation. 2010;20(3):378-86.

[37] Dembe AE. Social inequalities in occupational health and health care for work-related injuries and illnesses. International Journal of Law and Psychiatry. 1999;22(5-6):567-79.

[38] Messing K. One-eyed science: Occupational health and women workers. Philadelphia: Temple University Press; 1998. pp. 244. 
[39] Reid J, Ewan C, Lowy E. Pilgrimage of pain: The illness experiences of women with repetition strain injury and the search for credibility. Social Science \& Medicine. 1991;32(5):601-12.

[40] Premji S, Duguay P, Messing K, Lippel K. Are immigrants, ethnic and linguistic minorities over-represented in jobs with a high level of compensated risk? Results from a Montreal, Canada study using census and workers' compensation data. American Journal of Industrial Medicine. 2010;53(9):875-85.

[41] Premji S, Krause N. Disparities by ethnicity, language, and immigrant status in occupational health experiences among Las Vegas hotel room cleaners. American Journal of Industrial Medicine. 2010;53(10):960-75.

[42] Street TD, Lacey SJ. A systematic review of studies identifying predictors of poor return to work outcomes following workplace injury. WORK. 2015;51(2):373-81.

[43] King A. Making the law keep down the costs: Why Canada's public systems designed to support unemployed workers with a disabiality are making the decisoins that they are Toronto, ON: Centre for Research on Work Disability Policy; 2016 [Available from: https://www.crwdp.ca/en/newstudies].

[44] Stapleton J. The "welfarization" of disability incomes in Ontario Toronto: The Metcalf Foundation; 2013 [Available from: http://metcalffoundation.com/stories/publications/thewelfareization-of-disability-incomes-in-ontario/].

[45] Workplace Safety and Insurance Board. 2016 Workplace Safety and Insurance Board Annual Report. Toronto; 2016.

[46] Yachnin M. No evidence: The decisions of the Workplace Safety and Insurance Board. Toronto, ON: IAVGO Community Legal Clinic; 2017.

[47] Phelan SK. Constructions of disability: A call for critical relexivity in occupational therapy. Canadian Journal of Occupational Therapy. 2011;78:164-72.

[48] McCormack C, Collins B. Can disability studies contribute to client-centred occupational therapy practice? British Journal of Occupational Therapy. 2010;73(7):339-42.
[49] Rioux M, Valentine F. Does theory matter? Exploring the nexus between disability, human rights, and public policy. In: Pottier D, editor. Critical disability theory: Essays in philosophy, politics, policy and law. Vancouver: UBC Press; 2005.

[50] Charmaz K. Constructing grounded theory: A practical guide through qualitative analysis. Thousand Oaks; CA: Sage Publications Ltd.; 2006.

[51] Francis JJ, Johnston M, Robertson C, Glidewell L, Entwistle $\mathrm{V}$, Eccles MP, et al. What is an adequate sample size? Operationalising data saturation for theory-based interview studies. Psychology and Health. 2010;25(10):1229-45.

[52] Guest G, Bunce A, Johnson L. How many interviews are enough? An experiment with data saturation and variability. Field Methods. 2006;18(1):59-82.

[53] Flyvbjerg B. Case study. In: Denzin NK, Lincoln YS, editors. The SAGE handbook of qualitative research. 4th ed. Thousand Oaks, CA: SAGE Publications, Inc.; 2011. pp. 301-16.

[54] Schatzman L. Dimensional analysis: Notes on an alternative approach to the grounding of hteory in qualitative research. In: Maines DR, editor. Social organization and social process: Essays in honor of Anselm Strauss. New York: Aldine de Gruyter; 1991. pp. 303-14.

[55] Richards A. Where did they go? Scoping the ability to track social assistance outcomes for injured workers. Toronto, ON; 2016.

[56] Shaw L, MacAhonic P, Lindsay R, Brake P. Evaluating the support needs of injured workers in managing occupational transitions after injury. WORK. 2009;32(4):477-90.

[57] Strunin L, Boden L. Family consequences of chronic back pain. Social Science \& Medicine. 2004;58:1385-93.

[58] Storey. From invisibility to equality? Women workers and the gendering of workers' compensation in Ontario, 19002005. Labour/Le Travail. 2009;64:75-106. 